\title{
Protocol
}

\section{INTACT Proteomics in Xenopus}

\author{
Lauren Wasson, ${ }^{1,2}$ Nirav M. Amin, 2,3 and Frank L. Conlon¹,2,3,4 \\ ${ }^{1}$ Department of Genetics, University of North Carolina-Chapel Hill, Chapel Hill, North Carolina 27599; \\ ${ }^{2}$ University of North Carolina McAllister Heart Institute, University of North Carolina-Chapel Hill, Chapel Hill, \\ North Carolina 27599; ${ }^{3}$ Department of Biology, University of North Carolina-Chapel Hill, Chapel Hill, \\ North Carolina 27599
}

Analysis of the molecular mechanisms driving cell specification, differentiation, and other cellular processes can be difficult due to the heterogeneity of tissues and organs. Therefore, it is critical to isolate pure cell populations in order to properly assess the function of certain cell types in the context of a tissue. This protocol describes use of the INTACT (isolation of nuclei tagged in specific cell types) method in Xenopus, followed by proteomics analysis of nuclear protein complexes. The INTACT protocol utilizes two transgenes: (1) a three-part nuclear targeting fusion (NTF) consisting of a nuclear envelope protein (Nup35) that targets the NTF to the nuclear membrane, an enhanced green fluorescent protein (EGFP) cassette for NTF visualization in live animals, and a biotin ligase receptor protein (BLRP) that provides a substrate for the biotinylation of the NTF, and (2) the E. coli ligase BirA (which biotinylates the NTF) tagged to mCherry (for visualization). Either or both transgenes are driven by a tissue-specific promoter, making this protocol easily adaptable to proteomics analyses of immunoprecipitated complexes from INTACT-isolated nuclei of multiple tissue types to determine the composition of protein complexes in pure cell populations.

It is essential that you consult the appropriate Material Safety Data Sheets and your institution's Environmental Health and Safety Office for proper handling of equipment and hazardous materials used in this protocol.

RECIPES: Please see the end of this protocol for recipes indicated by $<R>$. Additional recipes can be found online at http://cshprotocols.cshlp.org/site/recipes.

\section{Reagents}

Acetonitrile, HPLC grade (Fisher A998)

BCA Protein Assay Kit (Pierce) (Thermo Fisher Scientific 23225)

BirA-mCherry transgene (Schaffer et al. 2010)

Synthesize capped BirA-mCherry mRNA constructs using the mMessage mMachine Transcription Kit (ThermoFisher Scientific AM1344 for T7, AM1348 for T3, or AM1340 for SP6) according to the manufacturer's protocol. Note that the enzyme used for transcription will depend on the RNA transcription promoter present in the $m R N A$ construct used (i.e., T7, T3, or SP6).

Dulbecco's phosphate-buffered saline (DPBS) (1×, pH 7.4) (Thermo Fisher Scientific 14040117)

\footnotetext{
${ }^{4}$ Correspondence: Frank_Conlon@med.unc.edu

From the Xenopus collection, edited by Hazel L. Sive.

(C) 2019 Cold Spring Harbor Laboratory Press

Cite this protocol as Cold Spring Harb Protoc; doi:10.1101/pdb.prot098384
} 
L. Wasson et al.

Ethanol (100\%)

Formic acid, LC-MS/MS grade $(99 \%+)$ (Pierce 28905)

Methanol

Nuclear purification buffer $(\mathrm{NPB})<\mathrm{R}>\left(\right.$ at $\left.4^{\circ} \mathrm{C}\right)$

In addition, prepare NPBb (NPB+0.5\% BSA) and NPBt (NPB +0.1\% Triton X-100).

Nuclear targeting fusion (NTF) transgene (Amin et al. 2014)

The NTF consists of three parts: a nuclear envelope protein (Nup35) that targets the NTF to the nuclear membrane, an EGFP cassette for NTF visualization in live animals, and a biotin ligase receptor protein (BLRP) that provides a substrate for the biotinylation of the NTF.

Clone the NTF transgene downstream of a tissue-specific promoter of choice (e.g., m/c2p or cardiac actin). For example, fusion downstream of the m/c2p regulatory element would drive NTF expression specifically in cardiomyocytes after stage 26 (Latinkic et al. 2004).

OptiPrep density gradient medium (Sigma-Aldrich D1556)

Prepare a solution of $30 \%$ OptiPrep in NPB.

Polyacrylamide gels and reagents for denaturing gel electrophoresis (Thermo Fisher Scientific)

NuPAGE $4 \%-12 \%$ Bis-Tris protein gels (NP0321)

NuPAGE antioxidant (NP0005)

NuPAGE LDS sample buffer $(4 \times)($ NP0008)

NuPAGE MOPS running buffer $(20 \times)$ (NP0001)

NuPAGE sample reducing agent $(10 \times)($ NP0009)

RIPA buffer for Xenopus $<\mathrm{R}>$

Streptavidin-conjugated magnetic Dynabeads (Invitrogen M-270)

Trypsin stock $(0.5 \mu \mathrm{g} / \mu \mathrm{L})$, sequencing grade (Promega V5111)

Store stock solution at $-80^{\circ} \mathrm{C}$ and limit to $<5$ freeze/thaw cycles.

Immediately before use, prepare a working solution of $12.5 \mathrm{ng} / \mu \mathrm{L}$ trypsin in $20 \mu \mathrm{L}$ of $50 \mathrm{~mm}$ ammonium bicarbonate.

Xenopus and reagents for transgenesis using REMI or method of choice (Amaya and Kroll 1999; Allen and Weeks 2005; Yergeau and Mead 2007)

Cell strainer $(100 \mu \mathrm{M})$ (Sigma-Aldrich CLS431752)

Centrifuge, refrigerated

Denaturing gel electrophoresis equipment

Embryo injector

Heat blocks at $37^{\circ} \mathrm{C}$ and $95^{\circ} \mathrm{C}$

Liquid chromatography system and mass spectrometer

We recommend using a Dionex Ultimate 3000 nanoRSLC system coupled to an LTQ-Orbitrap Velos mass spectrometer.

Liquid nitrogen

Magnet (Thermo Fisher Scientific 12321D)

Mortar and pestle, ceramic (Thermo Fisher Scientific FB961A-3 and FB961K-M)

Polytetrafluoroethylene tissue grinder

Razor blades

Rotator

Sonicator (Bioruptor [Diagenode])

Stopcock, two way (Thermo Fisher Scientific 6460)

Styrofoam cooler

Syringe needle

Transfer pipettes, plastic (Thermo Fisher Scientific 242) 
Tubes, polypropylene (conical, $15-$ and $50-\mathrm{mL}$ )

Tubes, polypropylene (rounded bottom, 2-mL)

Windex

\section{METHOD}

\section{Generating INTACT Nuclei in Xenopus}

This section describes generation of transgenic Xenopus embryos harboring the NTF transgene under control of a tissue-specific promoter and injected with or without BirA-mCherry mRNA.

1. Generate transgenic Xenopus containing the NTF transgene using REMI or the transgenesis method of choice (Amaya and Kroll 1999; Allen and Weeks 2005; Yergeau and Mead 2007).

Stable transgenic lines assure uniform expression; however, this method has been used successfully with transient (mosaic) transgenic animals (Amin et al. 2014).

2. Inject $1 \mathrm{ng}$ of BirA-mCherry mRNA into the transgenic Xenopus embryos at the 1-cell stage. As a negative control, generate NTF-transgenic embryos that do not receive BirA-mCherry injection. Injection at the 1-cell stage ensures distribution of BirA-mCherry throughout the entire developing embryo.

3. Culture the embryos to the desired stage of development.

Isolating INTACT Nuclei

This section describes the separation and isolation of nuclei from the NTF/BirA-mCherry transgenic embryos.

4. Harvest 100 embryos in $1 \times$ DPBS in a $2-\mathrm{mL}$ round-bottom tube. Wash the embryos three times with $1 \times$ DPBS by gently resuspending them using a plastic transfer pipette and then letting them settle to the bottom of the tube.

The required number of embryos should be determined empirically based on the percentage of cells in the embryos expressing the NTF. For most applications, 100 embryos should be sufficient; however, in instances where the NTF is only driven in a few cells (e.g., cardiac valve cells), more embryos will be required. Enough embryos should be harvested to recover $30 \mu \mathrm{g}$ of nuclear protein as measured by the BCA assay (Step 30).

5. Using a syringe needle, poke four holes in the cap of a 50-mL conical tube. Remove the cap and secure the tube into a rack in a Styrofoam cooler. Fill the cooler and tube with liquid nitrogen.

6. Using a plastic transfer pipette, drop the embryos into the conical tube containing liquid nitrogen, minimizing the volume of transferred DPBS. Once the embryos have been transferred, screw the cap onto the tube tightly. Remove the tube from the cooler (using a paper towel or cryo-glove for protection) and invert to drain the liquid nitrogen. Store the frozen tissue at $-80^{\circ} \mathrm{C}$.

7. Wash a ceramic mortar and pestle once each with the following: Windex, ethanol, methanol, and $\mathrm{ddH}_{2} \mathrm{O}$. Wipe dry with a paper towel. Carefully pour liquid nitrogen into the mortar and let it evaporate to cool the ceramic.

8. Carefully pour liquid nitrogen into the ceramic mortar, add the embryos, and grind the frozen embryos to a powder using a cold pestle. Collect the frozen powder in a $15-\mathrm{mL}$ conical tube.

9. Resuspend the frozen powder in $6 \mathrm{~mL}$ of NPB. Thaw the powder in NPB for $10 \mathrm{~min}$ on ice.

10. Transfer the lysate to a polytetrafluoroethylene tissue grinder and homogenize with 40 strokes.

11. Pass the lysate through a $100-\mu \mathrm{m}$ cell strainer into a $50-\mathrm{mL}$ conical tube.

12. Centrifuge the lysate at $1000 \mathrm{~g}$ for $10 \mathrm{~min}$ at $4^{\circ} \mathrm{C}$ to collect crude nuclei.

13. Resuspend the nuclei in $6 \mathrm{~mL}$ of $30 \%$ Optiprep in NPB. Centrifuge at $1000 \mathrm{~g}$ for $10 \mathrm{~min}$ at $4^{\circ} \mathrm{C}$ to harvest the enriched nuclei.

A small portion of this suspension can be analyzed by phase-contrast or stained with DAPI to determine nuclear purity. 
L. Wasson et al.

14. Wash the nuclei three times by gentle resuspension in $6 \mathrm{~mL}$ of NPB per wash.

Be sure to remove all traces of Optiprep before proceeding with subsequent steps.

\section{Affinity-Isolating INTACT Nuclei}

This section describes streptavidin-based isolation of nuclei. The addition of a large volume (9 mL) of NBPt ensures that contaminating cell types are washed away while the nuclei are preserved.

Perform Steps $15-26$ at $4^{\circ} \mathrm{C}$.

15. Resuspend the nuclei in $1 \mathrm{~mL}$ of NPB.

16. Incubate the nuclei with $50 \mu \mathrm{L}$ of streptavidin-conjugated magnetic beads. Rotate for $30 \mathrm{~min}$.

Proceed to Steps 17-19 during this incubation.

17. At the start of the incubation in Step 16, preload P1000 tips with $1 \mathrm{~mL}$ of NPBb per tip. Lay the preloaded tips on their sides.

18. After 20 min of incubation, insert a pre-loaded tip vertically into a two-way stopcock and attach it to a magnet. Open the stopcock and drain the NPBb from the P1000 tip.

19. Add $1.2 \mathrm{~mL}$ of NPBt to the broad opening of the stopcock assembly.

20. After the 30-min incubation (Step 16), add $9 \mathrm{~mL}$ of NPBt to the nuclei/bead mixture.

21. Resuspend the mixture in a $10-\mathrm{mL}$ pipette and insert it vertically into the broad opening of the stopcock assembly.

22. Slowly release the mixture through the stopcock assembly $(\sim 1 \mathrm{~mL} / 30 \mathrm{sec})$.

The bead-bound nuclei should be collected to the side of the P1000 tip by the magnet. The flow-through can be retained and processed through the remainder of the protocol (Steps 27-36) as a non-bead-bound control.

23. Remove the magnet and collect the bead-bound nuclei in a fresh tube in $1 \mathrm{~mL}$ of NPB.

24. Dilute the NPB/nuclei mixture $(1 \mathrm{~mL})$ to $10 \mathrm{~mL}$ with NPBt.

25. Add $1.2 \mathrm{~mL}$ of NPBt to the stopcock assembly.

26. Repeat Steps 21-23 with a new tip-magnet assembly.

\section{Proteomic Profiling INTACT Nuclei}

This section describes the lysis of nuclei, isolation and separation of protein complexes, digestion of proteins into peptides for mass spectrometry, and preliminary data analysis.

27. Resuspend the bead-bound nuclei in $100 \mu \mathrm{L}$ of RIPA buffer. Incubate for $10 \mathrm{~min}$ on ice to lyse the nuclei.

28. Sonicate the lysate using a Bioruptor on high for $15 \mathrm{~min}(30 \mathrm{sec}$ on $/ 30 \mathrm{sec}$ off $)$ at $4^{\circ} \mathrm{C}$.

29. Place the lysate on a magnet to elute the sample from the beads.

30. Measure the protein concentration using a BCA assay.

31. Add the appropriate amount of $4 \times$ LDS buffer and reducing agent to obtain a final concentration of $0.5 \times$ buffer to $30 \mu \mathrm{g}$ of protein sample. Incubate the sample for $10 \mathrm{~min}$ at $95^{\circ} \mathrm{C}$.

32. Load and run each sample on a $4 \%-12 \%$ Bis-Tris polyacrylamide gel. Add $500 \mu \mathrm{L}$ of antioxidant to the middle chamber before running. Load empty $1 \times$ sample buffer in all empty lanes to prevent uneven running of the gel.

We recommend $1 \times$ MOPS running buffer, since MOPS is ideally used to separate proteins between $14 \mathrm{kDa}$ and $>200 \mathrm{kDa}$, ensuring a thorough separation of the majority of the proteome.

33. Using a razor blade, slice each lane into 1-mm gel slices. Group 10 slices per sample.

34. Add trypsin $(12.5 \mathrm{ng} / \mu \mathrm{L})$ to the gel slices. Incubate overnight at $37^{\circ} \mathrm{C}$ to digest the proteins into peptides.

35. Extract the peptides in $0.5 \%$ formic acid/50\% acetonitrile (ACN). 
36. Analyze the peptides by nanoliquid chromatography-tandom mass spectrometry.

Search the spectra using a Xenopus-specific protein sequence database; see Greco et al. (2012) for a detailed protocol.

\section{DISCUSSION}

Studies of cellular and molecular pathways that are required for the development and maintenance of multicellular organs and tissues are notoriously difficult due to the heterogeneity of these structures. Many strategies have been implemented to isolate pure cell populations to circumvent these issues, including physical isolation by laser microdissection (Golubeva et al. 2013) or isolation based on the expression of a tissue or cell specific marker (FACS) (Barker et al. 1975). However, these methods of isolation require that the cell type of interest expresses a unique marker or reporter construct in order to ensure isolation of a pure population of cells. In Xenopus, isolation of cell populations using antibody-based sorting is difficult due to the availability of antibodies against these unique markers. The INTACT (isolation of nuclei tagged in specific cell types) method has been utilized in plants, worms, and flies to isolate pure nuclear populations via in vivo biotinylation of the nuclear envelope (Deal and Henikoff 2010, 2011; Henry et al. 2012; Steiner et al. 2012). The biotinylated nuclei are then isolated using streptavidin beads, separating nuclei from the cell population of interest away from other contaminating cell types without requiring an antibody. These studies have led to analysis of gene expression and chromatin features in Arabidopsis root epidermis cells (Deal and Henikoff 2011), distinct cell types in the Drosophila brain (Henry et al. 2012), and muscle cells from C. elegans (Steiner et al. 2012). This protocol describes the adaptation of the INTACT method for use in Xenopus, and subsequent proteomics analysis of nuclear protein complexes (Amin et al. 2014). The INTACT protocol utilizes two transgenes, the NTF transgene and the E. coli ligase BirA tagged to mCherry. Either or both transgenes are driven under the control of a tissue-specific promoter (e.g., the $m l c 2 p$ regulatory element fused upstream of the NTF to drive NTF expression specifically in cardiomyocytes after stage 26). The fact that the NTF can be expressed in a specific spatial and temporal manner makes this protocol easily adaptable to almost any cell or tissue type. Furthermore, proteomics analysis of immunoprecipitated complexes from INTACT-isolated nuclei of multiple tissue types can determine the composition of protein complexes in pure cell populations (Conlon et al. 2012).

A potential disadvantage of the INTACT method is that it requires the use of transgenic animals that express the NTF transgene. Ideally, stable transgenic lines would assure uniform expression of the transgene. Generation of stable transgenic lines can be technically challenging and time-consuming, however, and this method has been used successfully with transient (mosaic) transgenic animals (Amin et al. 2014).

\section{Nuclear Purification Buffer (NPB)}

10 mм Tris (pH 7.4)

$40 \mathrm{~mm} \mathrm{NaCl}$

$90 \mathrm{~mm} \mathrm{KCl}$

2 mM EDTA

0.5 mM EGTA

$0.2 \mathrm{~mm}$ dithiothreitol (DTT)

$0.5 \mathrm{~mm}$ phenylmethanesulfonyl fluoride (PMSF)

0.5 mu spermine (Sigma-Aldrich S3256)

$0.25 \mathrm{~mm}$ spermidine (Sigma-Aldrich S2626)

$1 \times$ Roche cOmplete Protease Inhibitor Cocktail (Sigma-Aldrich 11697498001)

Add DTT, PMSF, spermine, spermidine, and protease inhibitors to NPB immediately prior to use.

Use at $4^{\circ} \mathrm{C}$. 
L. Wasson et al.

\section{RIPA Buffer for Xenopus}

$50 \mathrm{~mm}$ Tris $(\mathrm{pH} 8.0)$

$150 \mathrm{~mm} \mathrm{NaCl}$

$0.5 \%$ sodium deoxycholate

$1 \% \mathrm{NP}-40$

$0.1 \%$ SDS

Store for up to $1 \mathrm{mo}$ at $4^{\circ} \mathrm{C}$.

\section{REFERENCES}

Allen BG, Weeks DL. 2005. Transgenic Xenopus laevis embryos can be generated using $\phi$ C31 integrase. Nat Methods 2: 975-979.

Amaya E, Kroll KL. 1999. A method for generating transgenic frog embryos. Methods Mol Biol 97: 393-414.

Amin NM, Greco TM, Kuchenbrod LM, Rigney MM, Chung MI, Wallingford JB, Cristea IM, Conlon FL. 2014. Proteomic profiling of cardiac tissue by isolation of nuclei tagged in specific cell types (INTACT). Development 141: 962-973.

Barker CR, Worman CP, Smith JL. 1975. Purification and quantification of $\mathrm{T}$ and $\mathrm{B}$ lymphocytes by an affinity method. Immunology 29: 765-777.

Conlon FL, Miteva Y, Kaltenbrun E, Waldron L, Greco TM, Cristea IM. 2012. Immunoisolation of protein complexes from Xenopus. Methods Mol Biol 917: 369-390.

Deal RB, Henikoff S. 2010. A simple method for gene expression and chromatin profiling of individual cell types within a tissue. Dev Cell 18: 1030-1040.

Deal RB, Henikoff S. 2011. The INTACT method for cell type-specific gene expression and chromatin profiling in Arabidopsis thaliana. Nat Protoc 6: $56-68$.
Golubeva Y, Salcedo R, Mueller C, Liotta LA, Espina V. 2013. Laser capture microdissection for protein and NanoString RNA analysis. Methods Mol Biol 931: 213-257.

Greco TM, Miteva Y, Conlon FL, Cristea IM. 2012. Complementary proteomic analysis of protein complexes. Methods Mol Biol 917: 391-407.

Henry GL, Davis FP, Picard S, Eddy SR. 2012. Cell type-specific genomics of Drosophila neurons. Nucleic Acids Res 40: 9691-9704.

Latinkic BV, Cooper B, Smith S, Kotecha S, Towers N, Sparrow D, Mohun TJ. 2004. Transcriptional regulation of the cardiac-specific MLC2 gene during Xenopus embryonic development. Development 131: 669-679.

Schaffer U, Schlosser A, Muller KM, Schafer A, Katava N, Baumeister R, Schulze E. 2010-SnAvi-A new tandem tag for high-affinity proteincomplex purification. Nucleic Acids Res 38: e91.

Steiner FA, Talbert PB, Kasinathan S, Deal RB, Henikoff S. 2012. Cell-typespecific nuclei purification from whole animals for genome-wide expression and chromatin profiling. Genome Res 22: 766-777.

Yergeau DA, Mead PE. 2007. Manipulating the Xenopus genome with transposable elements. Genome Biol 8(Suppl 1): S11. 


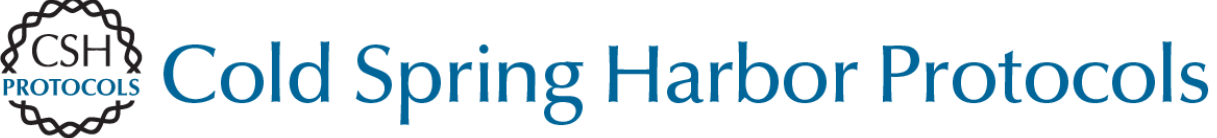

\section{INTACT Proteomics in Xenopus}

Lauren Wasson, Nirav M. Amin and Frank L. Conlon

Cold Spring Harb Protoc; doi: 10.1101/pdb.prot098384 originally published online August 27, 2018

\begin{tabular}{|c|c|}
\hline $\begin{array}{l}\text { Email Alerting } \\
\text { Service }\end{array}$ & Receive free email alerts when new articles cite this article - click here. \\
\hline $\begin{array}{l}\text { Subject } \\
\text { Categories }\end{array}$ & $\begin{array}{l}\text { Browse articles on similar topics from Cold Spring Harbor Protocols. } \\
\text { Cell Biology, general (1382 articles) } \\
\text { Developmental Biology (728 articles) } \\
\text { Immunoprecipitation ( } 75 \text { articles) } \\
\text { Preparation of Cellular and Subcellular Extracts (104 articles) } \\
\text { Proteomics (66 articles) } \\
\text { Subcellular Fractionation (88 articles) } \\
\text { Xenopus (210 articles) } \\
\text { Xenopus Transgenics (32 articles) }\end{array}$ \\
\hline
\end{tabular}

